\title{
STRATEGI PROMOSI JAMU TRADISIONAL REJO WALUYO DI PASAR PLAZA BANDAR JAYA LAMPUNG TENGAH
}

\author{
Oleh: \\ Thabita Carolina \\ Jurusan Ilmu Komunikasi, Universitas Tulang Bawang Lampung \\ e-Mail: thabitacarolina@gmail.com
}

\begin{abstract}
ABSTRAK
Warung jamu tradisional Rejo Wluyo merupakan warung jamu dengan konsep tradisional yang pertama kali ada di Pasar Plaza Bandar Jaya. Warung ini pada akhirnya mengilhami banyak masyarakat luas untuk membuat depot jamu seduh di Bandar Jaya. Penelitian ini bertujuan untuk mengetahui bagaimana strategi promosi yang digunakan oleh warung jamu tradisional dalam menarik minat konsumen sebagai pelanggan setia. Hal ini dilakukan untuk menghadapi persaingan yang cukup ketat dalam usaha jamu seduh di Bandar Jaya. Jenis penelitian ini adalah penelitian deskriptif kualitatif. Data pada penelitian ini diperoleh melalui wawancara, observasi dan studi pustaka.
\end{abstract}

Kata Kunci : strategi, strategi promosi, promosi, jamu tradisional Rejo Waluyo 


\section{PENDAHULUAN}

\subsection{Latar Belakang}

Indonesia merupakan Negara kepulauan

yang terletak di garis khatulistiwa membuat negara ini beriklim alam tropis. Hal ini menjadikan tanah Indonesia subur. Oleh karena itu sejak jaman nenek moyang dahulu masyarakat Indonesia banyak yang bercocok tanam mulai dari menanam untuk kebutuhan hidup sehari-hari sampai membuat apotek hidup.

Masyarakat Indonesia dalam situasi kondisi perekonomian yang kurang menguntunkan saat ini khususnya dibidang pemeliharaan kesehatan membuat kita kembali ke potensi alam nabati Indonesia. Dalam upaya menanggulangi berbagai penyakit dan gangguan kesehatan yang ditimbulkan akibat gaya hidup, pola makan, factor genetika, umur, kurang olahraga, stress, kegemukan dan lain sebagainya.

Potensi alam nabati ini kita kenal sejak jaman nenek moyang kita yaitu obat tradisional. Bahan dasar tanaman obat alami atau tradisional disekitar kita itu oleh masyarakat luas dikenal dengan istilah jamu. Warung jamu yang ada di wilayah Bandar Jaya sangat beragam jenisnya dan konsepnya. Ada jamu gendong yang sering kita temui di perkampun, ada warung jamu modern yang memiliki segmentasi menengah ketas dengan fasilitas lengkap. Semntara warung jamu Rejo Waluyo merupakan warung jamu tradisional dengan segmentasi menengah kebawah.

Warung Jamu Rejo Waluyo melakukan pengobatan herbal melalui warisan orang tua sejak turun temurun, melalui kegiatan seminar tentang jamu, secara Otodidak membaca bukubuku Literatur tentang manfaat jamu dan pengobatan. Akan tetapi harus disadari pula bahwa khasiat tumbuhan sebagai obat tergantung kepada banyak faktor, baik dari senyawa kimia yang dikandungnya maupun keadaan penyakit penderitanya. Warung jamu Rejo Waluyo memberikan 3 hal yang menarik minat konsumen menjadi setia, yaitu :

1. Anjuran

2. Pantangan

3. Sugesti

Strategi yang digunakan oleh Warung Jamu Rejo Waluyo sudah efektif, yang dibuktikan dengan semakin banyaknya jumlah konsumen dan jumlah pelanggan yang terus bertambah melalui Word Of Mouth (Dari Mulut ke Mulut) yang dilakuin oleh konsumen maupun pelanggan.

\subsection{Identifikasi Dan Masalah Pokok}

- Promosi yang dilakukan selama ini adalah melalui perorangan dan Kelompok / Golongan.

\subsection{Tujuan Penelitian}

- Untuk mengetahui mengapa masyarakat menengah ke bawah cenderung mengandalkan pengobatan jamu herbal.

\section{KERANGKA PEMIKIRAN}

\subsection{Kerangka Pemikiran}

Pengertian komunikasi ada tiga (Effendy, 1997:5), yaitu: Pertama, pengertian komunikasi 
secara Etimologis atau asal katanya yang berasal dari bahasa Latin Communication dan kata itu dari kata Komunis yang berarti sama makna yaitu sama mengenai suatu hal. Dalam bahasa Inggris berasal dari kata Communication yang diartikan sebagai memberitahu atau bertukar pikiran tentang pengetahuan, informasi, atau pengalaman seseorang. Kedua, pengertian komunikasi secara Terminologis adalah komunikasi merupakan proses penyampaian suatu pernyataan oleh seseorang kepada orang lain. Pengertian ini menjelaskan bahwa komunikasi ini melibatkan sejumlah orang dengan seorang yang lain menyatakan dan orang yang terlibat dalam komunikasi disebut Human Communication.

Ketiga, pengertian komunikasi secara Paradigmatis yaitu komunikasi yang berlangsung menurut suatu pola dan mempunyai tujuan tertentu dengan pola komunikasi sebenarnya mempunyai tujuan yaitu memberitahu, menyampaikan pikiran dan perasaan, mengubah pendapat maupun sikap.

\subsection{Hipotesis}

Berdasarkan masalah pokok pemasalahannya maka Hipotesis yang diajukan adalah : “ Apakah Strategi Promosi Warung Jamu Tradisional Rejo Waluyo sudah Efektif dalam memperoleh pelanggan setia di Wilayah Bandar Jaya, Kabupaten Lampung Tengah.

\subsection{Konseptual}

\section{a. Strategi}

Strategi adalah keseluruhan keputusan kondisional tentang tindakan yang akan dijalankan guna mencapai tujuan (Arifin,1994:35). Sedikitnya dari dua sudut pandang (Perspektif), yaitu berdasarkan :

a) Apa yang ingin dilakukan

b) Apa yang dilakukan

Menurut perspektif pertama, Strategi adalah program luas untuk menetapkan serta mencapai misi - misinya. Sedangkan perspektif yang kedua mengartikan strategi sebagai reaksi yang bersangkutan dengan lingkungan dan berlangsung nya waktu. (Effendy, 1997:32). Dalam penelitian ini, yang ingin dilakukan warung jamu Rejo Waluyo dan apa yang dilakukan warung jamu Rejo Waluyo agar konsumennya setia.

\section{b. Promosi}

Terdapat 5 jenis promosi yang biasa disebut sebagai bauran promosi, yaitu iklan, penjualan tatap muka, promosi penjualan, hubungan masyarakat dan Publisitas, serta pemasaran langsung (Kotler.2002:267). Bentuk - bentuk utama dari Komunikasi Pemasaran adalah penjualan perorangan (Personal Selling), iklan (Asvertising), promosi penjalan (Sales Promotion).

Informasi promosi yang diberikan kepada konsumen memiliki lima jenis dampak yang dapat diurutkan berdasarkan hirarki dampak yang dibutuhkan sebelum konsumen dapat atau ingin membeli sebuah produk. Dari sudut pandang manager pemasaran, dampak ini dapat 
diperlakukan sebagai urutan tujuan atau tujuan dari komunikasi pemasaran.

a) Konsumen harus memiliki kebutuhan yang disadari akan suatu kategori produk atau bentuk produk

b) Konsumen harus sadar akan merek

c) Konsumen harus memiliki merek positif

d) Konsumen harus memiliki keinginan untuk membeli merek

e) Konsumen harus melakukan berbagai macam perilaku untuk membeli suatu merek tertentu. (Shimp,2003:65)

Komunikasi pemasaran dapat membantu mempertemukan penjual dan pembeli bersama sama dalam suatu hubungan pertukaran, menciptakan arus informasi antara pembeli dan penjual yang membuat kegiatan pertukaran lebih Efisien dan kemungkinan semua pihak untuk mencapai persetujuan pertukaran yang dilakukan.

\section{c. Promosi Penjualan}

Promosi penjualan dapat digunakan untuk mendapatkan akibat jangka pendek seperti mendramatisir tawaran produk dan mendorong penjualan yang lentur. Promosi penjualan berisikan bermacam-macam insentif, bersifat jangka pendek, yang didesain untuk menstimulasi pembelian segera atau lebih banyak produk oleh konsumen ataupun pembeli bisnis (Simamora,2001:330). Promosi menawarkan insentif untuk pembeli.

\section{d. Pengertian Jamu Herbal}

Pengertian tentang Obat Tradisional adalah tanaman alam Nabati dan rempah - rempah yang ada di alam sekitar kita yang di ramu atau diracik untuk pengobatan sakit penyakit tertentu dan menjaga kesehatan umat manusia. Petunjuk umum meramu dan menggunakan ramuan ada beberapa hal yang harus di perhatikan sebagai berikut :

\section{Tata Nama}

2. Ruang Lingkup

3. Berat dan Dosis

4. Jangka Waktu

5. Peralatan

6. Bahan Baku

7. Air juga dibutuhkan untuk ramuan yang tida direbus

8. Kegunaan

9. Cara meramu

10.Aturan pakai ramuan harus ditepati dan disesuaikan tingkat unsur penggunaannya.

\section{e. Obat Tradisional}

Berdasarkan pengalaman, Obat-Obatan Tradisional aman, bermanfaat serta dapat diterima oleh masyarakat. Hal ini terlihat dari adanya kecenderungan waktu meningkatnya penggunaan obat-obatan traisional dari waktu ke waktu. Adapun beberapa faktor yang mendukung bertahannya penggunaan Obat Tradisional, diantaranya sebagai berikut:

1) Mudah pembuatannya

2) Murah

3) Tidak ada Efek Samping 


\section{f. Khasiat Dan Kegunaan Jamu Tradisional}

Tidak sedikit jenis penyakit yang menjangkiti tubuh manusia, disebabkan karena kekurangan Vitamin. Karena itu agar badan tetap sehat, diharuskan menjaga makanan yang mengandung cukup Mineral dan Vitamin. Vitamin di bentuk didalam makanan, terutama sayuran segar, dan juga buah - buahan. Berikut ini beberapa macam Vitamin yang telah dikenal yaitu :

1. Vitamin A

2. Vitamin B kompleks

3. Vitamin B2 (Ribovlafin)

4. Vitamin C (Ascobir Acid)

5. Vitamin E

\section{g. Pemasaran obat/jamu tradisional}

Adanya perkembangan atau meningkatnya jumlah penggemar jamu disebabkan oleh cara pemasarannya yang kian maju. Dulu hanya dijual oleh kaum wanita dengan cara menggendongnya dan berjalan dari gang ke gang. Tetapi sekarang sudah menggunakan sepeda, gerobak dorong, sepeda motor, sehingga memungkinkan jangkauan pemasaran yang luas. Adapun macam-macam atau jenis Jamu Tradisional yang dipasarkan adalah;

1. Jamu Beras Kencur

2. Jamu Kunir Asam

3. Jamu Pahit

4. Jamu Cabe Puyang

5. Jamu Galian

6. Jamu Bandrek
Tetapi penulis tetap berharap Strategi Komunikasi dalam Pemasaran Produk Jamu Tradisional harus memperhatikan beberapa hal berikut ini;

1. Kemasan

2. Pemasaran

3. Harga jual terjangkau tergantung daerah dan situasi setempat

4. Mutu

\section{METODE PENELITIAN}

\subsection{Jenis Penelitian}

Jenis penelitian yang dilakukan adalah penelitian Kwalitatif, yaitu penelitian yang bersifat memaparkan situasi dan peristiwa, datanya dinyatakan dalam keadaan sewajarnya atau sebagaimana adanya, dengan memaparkan cara kerja yang bersifat sistematis, terarah dana dapat dipertanggung jawabkan.

\subsection{Lokasi Penelitian}

Lokasi penelitian di lakukan di Warung Jamu Rejo Waluyo, yang beralamat di Pasar Plaza Bandar Jaya.

\subsection{Obyek Penelitian}

Obyek penelitian yang diambil oleh Penulis (Peneliti) Warung Jamu Rejo Waluyo, Plaza Bandar Jaya - Kabupaten Lampung Tengah, Propinsi Lampung.

\subsection{Teknik Pengumpulan Data}

Untuk pengumpulan data yang diperlukan penulis menggunakan atau menempuh cara sebagai berikut :

a. Untuk memperoleh data sekunder 
b. Untuk mendapatkan data Primer

\subsection{Data Dan Sumber Data}

Data yang di butuhkan adalah data tentang Strategi Komunikasi Produk Jamu Tradisional Rejo Waluyo dalam menarik minat konsumen sebagai pelanggan yang setia. Para Responden di minta menjawab sesuai pendapat mereka atas pertanyaan - pertanyaan yang telah di persiapkan dalam Interview Guide tentang Strategi Komunikasi Pemasaran Produk Jamu Rejo Waluyo Di Bandar Jaya dalam menarik minat konsumen sebagai pelanggan setia. Data yang dibutuhkan dalam penelitian di bagi dua bagian :
a. Data primer
b. Data sekunder

\subsection{Tehnik Analisis Data}

Analisis data adalah proses penyederhanaan data dalam bentuk yang sudah dibaca. Analisis data yang akan dipergunakan dalam penelitian ini adalah analisis data Kwalitatif, yaitu data yang diperoleh langsung melalui Wawancara, Observasi, dan Studi Pustaka, data yang diperoleh kemudian dianalisis dengan data atau obyek yang di teliti dan menginterprestasikan berdasarkan kerangka teori yang ada untuk memperoleh kesimpulan. Analisis yang dilakukan mengacu pada Strategi Komunikasi Pemasaran dengan menjalankan Proses Komunikasi dalam membangun loyalitas atau kesetiaan konsumen.
a. Pengumpulan Data
b. Reduksi Data
c. Penyajian Data

d. Menarik Kesimpulan

Gambar 3.1

PROSES SIKLUS INTERAKTIF

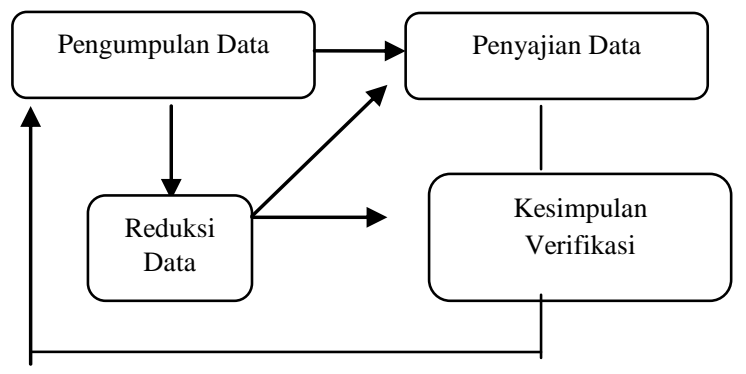

(Sumber : Huberman Dan Miles 1992 : 20)

\subsection{Uji Validassi}

Untuk mendapatkan data yang memenuhi Kredibilitas dapat dilakukan kegiatan sebagai berikut :
a. Keterlibatan peneliti secara cukup (Prolonged Engagement) di lokasi penelitian dalam berinteraksi dengan subjek peneliti.
b. Ketelitian dalam pelaksanaan Observasi
(Presistent Observation) secara
Ketelitian dalam pelaksanaan Observasi
(Presistent Observation) secara Partisipatif.
Triangulasi (Triangulations) Partisipatif.
c. Triangulasi (Triangulations)

GAMBAR 3.2 SKEMA SUMBER DATA

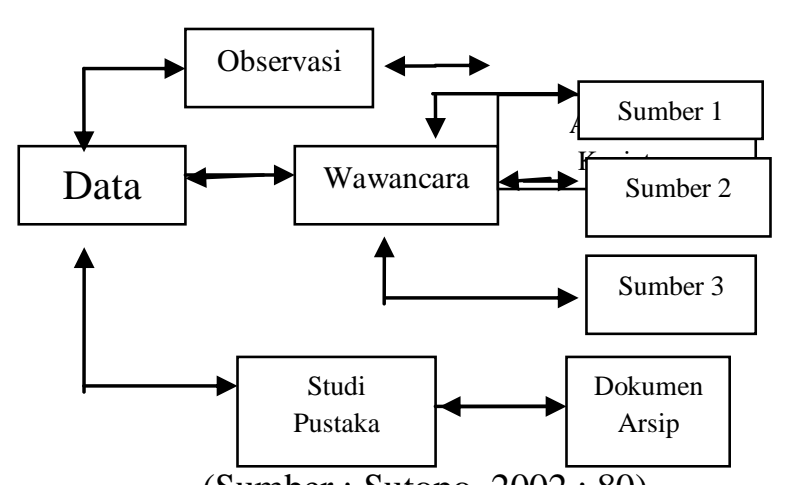

(Sumber : Sutopo, $2002: 80$ ) 


\section{HASIL PENELITIAN}

\subsection{Gambaran Umum Warung Jamu Rejo Waluyo}

Warung Jamu Rejo Waluyo adalah salah satu warung jamu dengan nuansa dan konsep tradisional yang dirancang sedemikan rupa, sehingga diminati berbagai kalangan (khususnya menengah kebawah) dengan memberikan suasana kekurangan.

Lokasi Warung Jamu Rejo Waluyo berada di Blok D.4 No.6/7 Plaza Bandar Jaya Kabupaten Lampung Tengah, Propinsi Lampung. Buka setiap hari dari pukul 08.00 WIB sampai dengan pukul 14.30 WIB. Adapun omset rata - rata Warung Jamu Tradisional Rejo Waluyo berkisar Rp.1.000.000 - Rp.1.500.000,per hari. Sasarannya adalah para perajin jamu gendong, tabib, pengobatan alternatif, pengingat jamu herbal, Bahkan untuk konsumsi sendiri dalam rumah tangga.

\subsubsection{Sejarah dan Perkembangan Warung Jamu Tradisional Rejo Waluyo}

Menurut cerita orang tua yang bernama Bapak Rejo Utomo dan Ibu Sanikem pada tahun 1968 mulai merintis jamu tradisional Jawa asli. Berdasarkan Ilmu Otodidak dan kebiasaan orang tua pada waktu itu mewarisi manfaat tanaman obat sekitar rumah kita yang kemudian menjawab kebutuhan di masyarakat perlunya pengobatan tradisional dengan rintisan jamu gendong.
Pada tahun 1998 jamu gendong tradisional yang dikenal dengan jamu Mbah Waluyo, maka di daftarkan merk "Jamu Tradisional Rejo Waluyo" Warung Jamu Rejo Waluyo bertujuan menjawab kebutuhan di masyarakat akan pentingnya jamu untuk kesehatan secara alami.

Melihat perkembangannya Warung Jamu Tradisional Rejo Waluyo yang makin hari makin meningkat dan makin banyak pengunjung, maka Agus Sumarwan selaku pemilik Warung Jamu Rejo Waluyo semakin terpacu untuk meningkatkan mutu pelayanan sebagai penghargaan terhadap para pelanggan yang datang. Lebih dari pada pelayanan yang ramah dan nyaman, pengunjung mendapatkan kesanyang positif sehingga keluhan atau sakit penyakit yang diderita berangsur membaik dan sembuh.

\subsubsection{Visi, Misi dan Tujuan Warung Jamu Rejo Waluyo}

4.1.2.1. Visi Warung Jamu Rejo Waluyo

a. Menjadi ruang publik dengan unit usahanya tentang jamu tradisional, sehingga menjadi pilihan pertama bagi pelanggan penggiat dan penikmat jamu tradisional.

b. Menjadi ruang publik sebagai tempat informasi dan berdialog tentang rujukan jamu tradisional.

c. Menjadi industri rumah tangga dan menyuplai bahan baku jamu herbal yang berkwalitas.

\subsubsection{Misi Warung Jamu Rejo Waluyo}


a. Menyediakan macam - macam Jamu Herbal (Basah, Simplesia, Akar, Kayu, Daun, Kulit, Buah, Biji)

b. Menciptakan ruang publik yang Familiar dan bersahabat sekaligus menyediakan Sarana dan Prasarana informasi dalam berkomunikasi.

c. Menyediakan dan melayani permintaan atau pesanan dalam bentuk Instan, Bubuk, ramuan yang direbus, maupun koleksi Apotik Hidup.

\subsubsection{Tujuan Warung Jamu Rejo Waluyo}

a. Melengkapi sajian jamu tradisional yang dipesan dan dikonsumsi pelanggan

b. Memberikan informasi yang akurat tentang manfaat jamu tradisional untuk kesehatan

c. Melengkapi fasilitas, sarana dan prasarana dengan teknologi tepat guna.

d. Menjadi tujuan yang pertama dan utama untuk mengetahui manfaat jamu herbal sebagai suplemen.

\subsubsection{Struktur Usaha Warung Jamu Rejo Waluyo}

Secara garis besar Jabatan didalam Struktur Usaha Warung Jamu Rejo Waluyo adalah sebagai berikut :
a. Pimpinan (OWNER)
b. Asisten Umum
c. Kasir atau Keuangan
d. Logistik (Gudang)
e. Teknik Service
f. Produksi

g. Karyawan Pemasaran

\subsubsection{Konsep Manajemen Warung Jamu Rejo Waluyo}

Konsep Manajemen Warung Jamu Rejo Waluyo terdiri dari beberapa bagian sesuai dengan tugas dan bidangnya yang masing masing bertanggung jawab terhadap asisten umum yang merangkap personalia.

Konsep manajemen dan Struktur Usaha Warung Jamu Rejo Waluyo diharapkan bisa memudahkan dalam koordinasi dalam operasional sehingga bisa memotivasi dalam memajukan Warung Jamu Tradisional Rejo Waluyo di Plaza Bandar Jaya Kabupaten Lampung Tengah, Provinsi Lampung.

\subsubsection{Karyawan Warung Jamu Rejo Waluyo}

Karyawan Warung Jamu Rejo Waluyo berjumlah 11 orang dengan klasifikasi bahwa :

1. Bagian Manajemen : 3 orang

2. Karyawan Pemasaran : 3 orang

3. Karyawan Tidak Tepat : 5 orang

\subsubsection{Strategi promosi Warung Jamu Rejo Waluyo - Plaza Bandar Jaya}

Pelayanan yang baik adalah nilai inti jamu Rejo Waluyo. Pelayanan yang bagus tercipta karena setiap orang melakukan hal yang tepat pada waktu yang tepat, dalam cara yang tepat, untuk orang yang tepat dan dengan hasil yang terbaik. Sesungguhnya pelayanan yang baik adalah hasil dari setiap proses yang memenuhi persyaratan pelanggan, dan tercapainya kepuasan yang maksimal pada tingkat biaya 
yang serendah mungkin. Ada 4 (Empat) langkah yang diyakini menjadi kekuatan di belakang strategi Warung Jamu Rejo Waluyo dalam menghadapi persaingan dalam arti persaingan bisnis antara lain :

a. Merentangkan tujuan / target keluar batas - batas yang normal (Strerch The Goal) merupakan langkah nyata dalam meraih kinerja pelayanan diatas rata rata, dengan demikian selalu di persepsi yang terbaik oleh pelanggan.

b. Menyederhanakan (Simplify)

c. Menjadikan Kwalitas sebagai pekerjaan setiap orang (Quality is My Job)

d. Memberikan penghargaan kepada pemenang (Reward The Winners)

Warung Jamu Tradisional Rejo Waluyo semaksimal mungkin memberikan fasilitas yang dirasa mencukupi kebutuhan konsumen fasilitas yang ada saat ini adalah :

- Meja panjang dengan kapasitas 6 orang tiap kursinya sambil menunggu antri giliran minum jamu seduhan.

- Meja panjang ada 2 dan kursi ada 12 buah.

- Ada ruang tunggu yang dilengkapi Televisi 21 inc.

- Ada kipas angin.

- Papan informasi yang digunakan untuk memasang publikasi acara yang berkaitan dengan Event Jamu Tradisional.

- Brosur dan buku - buku tentang jamu herbal.
Produk - produk jamu tradisional yang di jual oleh Warung Jamu Rejo Waluyo tidak hanya jamu seduh yang diminum saja, tetapi juga seperti :

1. Ramuan Rempah Ratus untuk direbus minuman suplemen.

2. Bubuk Tawar Empon - Empon.

3. Bubuk Instan Empon - Empon ada 7 macam (Temu Lawak, Kunir, Jahe Merah, Bandrex, Kencur, Temu Putih, Kunir Putih).

4. Racikan Rempah Kayu secang untuk mandi gatal - gatal.

5. Bahan baku jamu mentah.

6. Distributor dari Supplier Jamu Air Mancur, Sido Jodo, Sido Muncul, Gujati, Nyonya Mener, Leo, Jago dan lain - lain.

Menurut bagian pemasaran Warung Jamu Tradisional Rejo Waluyo, kegiatan komunikasi pemasaran dilakukan untuk memberikan informasi dan meningkatkan promosi tentang produk yang dihasilkan. Strategi komunikasi pemasaran warung jamu Tradisional Rejo Waluyo dilakukan secara bertahap dengan melihat situasi dan kondisi pasar kemudian disesuaikan dengan kemampuan yang ada.

Warung Jamu Rejo Waluyo tidak hanya melayani permintaan jamu saja tetapi juga suasana yang hangat, tempat informasi tentang jamu herbal, tempat bertemu banyak orang, dan tempat untuk melepas penat. Pelanggan Warung Jamu tradisional Rejo Waluyo dari berbagai kalangan antara lain : Para Remaja dan ibu - ibu 
yang mengalami gangguan kewanitaan, ibu bersalin, ibu menyusui, para petani, para buruh kasar, dan pekerja berat. Mereka semua membutuhkan jamu untuk suplemen yang berkasiat untuk memulihkan tenaga dan menjaga stamina tetap sehat beberapa respounden yang diwawancarai penulis salah satunya Ibu Paini seorang ibu yang berprofesi menjual sayuran di pasar Bandar Jaya, kemudian Mbak Betty yang tinggal di Bumi Kencana, juga Mbak Suminah penjual chiki di pasar Bandar Jaya, mereka adalah pelanggan Jamu Rejo Waluyo sampai sekarang.

\subsection{Pembahasan}

\subsubsection{Proses Komunikasi Pemasaran}

Ada Tiga unsur pokok struktur proses komunikasi pemasaran yaitu : Pelaku Komunikasi, Matrial Komunikasi, dan Proses Komunikasi. Di Warung Jamu Rejo Waluyo yang berperan sebagai pelaku komunikasi adalah Warung Jamu Rejo Waluyo sebagai komunikatornya dan konsumen sebagai komunikasinya. Matrial komunikasi yang ada dalam proses komunikasi antara warung jamu dan konsumen adalah gagasan yang berupa program pemasaran yang disusun oleh manajemen kemudian diolah untuk menghasilkan Autput merupakan Strategi komunikasi pemasaran media yang digunakan untuk menyampaikan strategi komunikasi pemasarannya adalah para karyawan Warung Jamu Rejo Waluyo dan media pendukung komunikasi lainnya seperti : Banner, Sticker, Kalender, Kaos.

Proses komunikasi berupa penyampaian pesan maupun pengiriman kembali respon akan memerlukan dua kegiata, yaitu :

1. Encoding yaitu merubah gagasan menjadi pesan agar menjadi Feed Back dan pihak Warung Jamu Rejo Waluyo menerima pesan dari konsumen.

2. Decoding untuk kemudian di Encoding lagi dan seterusnya.

\subsubsection{Strategi Komunikasi Pemasaran Warung Jamu Rejo Waluyo}

Pada tahap perencanaan Warung Jamu Rejo Waluyo, awalnya mensegmentasikan warungnya untuk para perantau dari pulau jawa. Tetapi yang terjadi tidak hanya suku jawa saja yang datang sebagai konsumen, melainkan berbagai latar belakang suku yang sebelumnya sangat asing dengan jamu ternyata mau menikmati dan menjadi pelanggan pada Warung Jamu Rejo Waluyo. Perencanaan yang sudah dilakukan Warung Jamu Rejo Waluyo hanya merupakan perencanaan awal dalam sebuah strategi komunikasi.

\subsubsection{Implementasi}

Konsumen atau pelanggan yang datang ke Warung Jamu Rejo Waluyo adalah :

- Orang perantau yang menyukai Jamu Tradisional. 
- Karna mempunyai keluhan sakit penyakitnya sehingga ingin mencoba pengobatan secara tradisional.

- Orang - orang yang berasal dari latar belakang yang sudah menjadi pelanggan tetap Warung Jamu Rejo Waluyo.

Penerapan posisioning agar sampai pada tingkatan Mindshare dan Headshare konsumen dilakukan dengan cara tetap menjaga cita rasa yang khas Jamu Rejo Waluyo. Unsur Emosional bisa di dapatkan ketika pelanggan mendapatkan Surprise dan hal tersebut merupakan fase ketiga tahapan loyalitas konsumen yaitu : Fase Spiritual yang akhirnya konsumen merekomendasikan Produk (Evangelist) bukan berarti pelanggan tersebut akan loyal.

\subsubsection{Loyalitas Konsumen}

Tahapan kepuasan pelanggan dibagi menjadi tiga fase yaitu : Rasional, Emosional, dan Spiritual. Fase rasional memiliki unsur dasar kepuasan pelanggan, fase emosional indikasinya adalah repitisi pembelian, dan fase spiritual terjadi ketika konsumen merekomendasikan produk yang digunakan kepada orang lain. Pelanggan yang diwawancarai oleh penulis mengatakan selalu puas ketika datang ke Warung Jamu Rejo Waluyo. Harapan dan tujuan mereka ketika hendak datang ke Warung Jamu Rejo Waluyo selalu terpenuhi meskipun harus antri menunggu giliran.

\subsubsection{Evaluasi}

Warung Jamu Rejo Waluyo tidak melakukan Evaluasi melalui Kuisioner dikarenakan hal tersebut dirasa oleh Om Maman masih belum perlu dilakukan karena mayoritas pengunjung bisa langsung menyampaikan keluhannya kepada Pelayan (Karyawan) yang nantinya akan menjadi bahan masukan untuk manajemen Warung Jamu Rejo Waluyo.

\section{PENUTUP}

\subsection{Kesimpulan}

1. Warung Jamu Rejo Waluyo adalah warung jamu dengan konsep tradisional.

2. Konsep tradisional yang disuguhkan Warung Jamu Rejo Waluyo kepada konsumennya meliputi beberapa macam produk antara lain : Bedak untuk Luluran, Jamu Rempah Kayu, Secang untuk mandi, Jamu Rempah Ratus untuk beberapa macam penyakit dan masih banyak lagi produk andalan yang lain.

3. Dalam menjalankan Program Komunikasi Pemasarannya, Warung Jamu Rejo Waluyo selaku berpegang teguh kepada Visi dan Misi Warung Jamu Rejo Waluyo sebagai ruang publik yang salah satu tujuannya adalah sebagai pilihan pertama tentang jamu, tempat informasi, tempat bersosialisasi, sekaligus tempat rujukan tentang Jamu Herbal.

4. Positioning Statenent dalam Slogan dan Moto Warung Jamu Rejo Waluyo cukup Menarik, Unik, dan Pas dengan segmen Warung Jamu Rejo Waluyo, serta cukup 
sebagai diferensiasi Warung Jamu Rejo

Waluyo dengan depot jamu lainnya.

5. Strategi pengeluaran promosi yang di lakukan Warung Jamu Rejo Waluyo tergantung pada Situassi Pasar, Segmentasi, Karakteristik Konsumen, dan kebijakan anggaran promosi.

6. Strategi Komunikasi Pemasaran yang dilakukan Warung Jamu Rejo Waluyo mayoritas, merupakan hasil dari komunikasi yang terjadi antara konsumen dengan pihak Warung Jamu Rejo Waluyo, yang kemudian di teruskan kepada pembuat kebijakan untuk direspon dan ditindak lanjuti Warung Jamu Rejo Waluyo menggunakan kasir dan karyawan pemasaran sebagai kepanjangan tangan dari pihak manajemen dalam melakukan sosialisasi program atau event yang akan diadakan oleh Warung Jamu Rejo Waluyo.

7. Dalam melakukan Strategi Komunikasi Pemasaran, selain dari pada melalui para pelanggan (dari mulut ke mulut) media pendukung lain yang digunakan Warung Jamu Rejo Waluyo adalah : Iklan, Poster, Banner, Sticker, Kalender.

8. Cara unik untuk mendekati pelanggan dan konsumen adalah dengan mempersilakan konsumen Warung Jamu Rejo Waluyo. Untuk melihat cara produksi langsung jamu ala Rejo Waluyo, hingga peracikan jamu siap saji, sampai dengan kemasan yang bisa di bawa pulang. Ke unikan yang lain adalah : Pemberian Surprise kepada pelanggan Warung Jamu Rejo Waluyo yang dilakukan secara Spontan oleh Kasir.

\subsection{Saran}

1. Mempertahankan Konsep Tradisional Warung Jamu Rejo Waluyo dengan mempertahankan seting tempat, tempat duduk yang nyaman, harga produk terjangkau, pelayanan yang akrab.

2. Menambah ruang konsumen sebagai langkah meminimalisir kekecewaan konsumen ketika ingin Meminum Jamu Rejo Waluyo tetapi kehabisan tempat dengan menambah meja, kursi atau ruang duduk di Warung Jamu Rejo Waluyo.

3. Penerapan Experiental Marketing secara tepat dan meyeluruh dalam Strategi Komunikasi Pemasaran Warung Jamu Rejo Waluyo dengan cara memberikan aroma khas di sekitar Warung Jamu Rejo Waluyo, meja atau ruang konsumen terlihat bersih, suasana ceria pelayanannya, komunikasi yang baik antara pelanggan dan karyawan, pelayanan yang tepat dan tanggap.

4. Menggunakan media promosi yang lebih bervariasi untuk meningkatkan perhatian publik dan memperkuat Posisioning yang kuat diantara Kompetitor Warung Jamu Rejo Waluyo. 
5. Dengan mengikuti Event Pameran, kegiatan seminar tentang Jamu Herbal, maka Kreatifitas akan berkembang untuk kemajuan Warung Jamu Rejo Waluyo, tanpa menghilangkan ciri Khas Tradisional.

\section{DAFTAR PUSTAKA}

Tony Greener : Kiat Sukses Public Relations, Radar Jaya Offset (Jakarta 1993).

Dr. Setiawan Dalimartha : Atlas Tumbuhan Obat Indonesia, Trubus Agriwidya (Jakarta 1999).
R. Broto Sudibyo,Bsc : Ramuan Tradisional Ala Eyang Broto, PT. Penebar Swadaya (Jakarta 2006).

Mulyana, Deddy : Ilmu Komunikasi Suatu Pengantar, Remaja Rosdakarya (Bandung 2005).

Tjiptono, Fandy : Strategi Komunikasi Pemasaran, Andi Offset (Yogyakarta 1997).

Rakhmat, Jalaluddin : Metode Penelitian Komunikasi, PT. Remaja Rosdakarya (Bandung 2005). 